\title{
Self-Scheduling of Wind Power Generation with Direct Load Control Demand Response as a Virtual Power Plant
}

\author{
Mehrdad Tahmasebi* and Jagadeesh Pasupuleti \\ Department of Electrical Power Engineering, Universiti Tenaga Nasional, 43000 Kajang, Selangor, Malaysia; \\ tahmasebi86@gmail.com,Jagadeesh@uniten.edu.my
}

\begin{abstract}
A virtual power plant, VPP, defined as a collection of dispersed generator units, storages and controllable load systems aggregated as a unique power plant. VPPs were categorized as Commercial virtual power plant, CVPP and Technical virtual power plant, TVPP. CVPP was related to the market and expected to obtain a maximum benefit from the generation and demand portfolio. The TVPP takes into consideration the operation of the grid and expected to solve possible contingencies. Two technologies that could be offered as a CVPP were wind power producer, WPP, and Flexible consumption especially direct load control, DLC, demand response program. This work focused on the economic operation of CVPP consisting of WPP and DLC in a competitive electricity market and the WPP intermittent compensation. The researcher in this paper used self-scheduling, SS, method to derive maximum expected profit from the Energy Markets. The problem of selfscheduling of the CVPP was formulated and solved by GAMS software. The case study and numerical results were presented in this paper.
\end{abstract}

Keywords: Virtual Power Plant (VPP), Distributed Energy Resource (DER), Wind Power Producer (WPP), Direct Load Control (DLC), Self-Scheduling (SS).

\section{Introduction}

Creation and use of renewable energy resources have become important due to global warming and environmental issues associated with the usage of fossil fuels. Among the renewable energy resources wind power generation is preferred choice in terms of usage and importance. The issues concerning about energy security, fuel price instability, and the environmental challenges, and diversification of energy resources makes the increased use of wind energy. Unlike other types of renewable energy resources, wind technology is the result of the development of wind generators over traditional units with comparable cost and capacity ratings [1].
One of the major objectives of WPP consisting of large number of wind power plants is to increase their profit. This goal can be achieved with the pay incentives for wind farms and other policies such as integration of demand response (DR) as a unique virtual power plant, VPP. Technologies that exploit DR and Demand Side Management (DSM) are one of the choices that must be considered in system planning, due to the commercial probability of regulating consumption in response to the variation in wind power generation [2]. In this study, we discuss how the DR programs with regard to consumption can efficiently raise profit of the VPP and perform operations scheduling of power systems are investigated. Direct Load Control (DLC) is DR program that is considered in this study.

${ }^{*}$ Corresponding author:

Mehrdad Tahmasebi (tahmasebi86@gmail.com) 
The rest of this paper is organized in the following order. Section 2 describes the VPP, wind power generation and demand response programs. Section 3 presents the mathematical formulation of the proposed framework. Section 4 presents a numerical case study and the discussion about the results. Finally, the last section is devoted to the conclusion.

\section{Virtual Power Plant (VPP) Concept}

The Virtual Power Plant is quite a new concept. A virtual power plant, VPP, is a collection of dispersed generator units, storages and controllable load systems aggregated as a unique power plant [3]. Flexible Electricity Networks to integrate the expected 'energy evolution' (FENIX) project defines A Virtual Power Plant (VPP) as: "VPP aggregates the capacity of many diverse DERs to create a single operating profile from a composite of the parameters characterizing each DERs and incorporates the impact of the network on aggregate DERs output" [4]. A VPP is a flexible representation of a portfolio of DERs that can be used to make contracts in the wholesale market and to offer services to the system operator [5]. The VPP concept is closely related to DER aggregation. DER is normally referred as small-scale generation and storage technologies. Because the active demand can make the same contribution to help the power system operation as the generation/storage technologies do, it is also included in the category of DER [6]. The VPP can be classified into two categories: Technical VPP, TVPP, and Commercial VPP, CVPP. CVPP, which is related to the market, obtains a maximum benefit from the generation and demand portfolio without further considerations. CVPP provides services to the system operator including balancing or trading portfolios and trading in the wholesale energy market. TVPP consisting of DER from the same geographic location receives an income mainly from the system operator not from the market. TVPP will take into consideration the operation of the grid and tries to solve possible contingencies [7].

\subsection{Wind Power Generation}

The use of wind power increases from year to year because of low operating cost and advanced technology. Despite these advantages, the use of wind power has several drawbacks; the most critical drawback is the uncertainty.
This problem is more serious in the power market. Hence, some amount of reserve is necessary to support wind generation. To solve these problems and improve the flexibility of the network, several technical and financial schemes proposed in recent years $[1,8,9]$.

Wind Power Producer (WPP), who are contributing in the day ahead market, must submit their bids a few hours before operation. In the Spanish power market, offer period is typically $12-36 \mathrm{~h}$ ahead [10]. Therefore, WPP need a tool to short term prediction of its power generation $[11,12]$. However, the wind energy prediction tools do not as accurate.

\subsection{Demand Response Programs}

DR in this explanation can be classified into two clusters: Time-Based Rates (TBR) and Incentive-Based Program (IBP) demand response. Several sub groups are illustrated in the following chart (Figure 1) [13].

Changes in usage by consumers in response to variations in the payment prices are mentioned to Time-based demand response programs. The TBR contains time-ofuse, critical-peak pricing and real-time pricing rates sub groups. Considering that in particular time the price rate increases or sometimes decreases, thus consumers can change the use of energy based on those hours; therefore, planning the timing for employing electricity to the grid is of prominent importance.

Another cluster that is taken into account for demand response is incentive-based program (IBP). IBP are recognized by a regional grid operator, load serving entities or utilities. IBP contain EDRP, DLC, I/C, CAP, Ancillary Service (A/S) and Demand Bidding (DB) programs. EDRP and DLC are free choice programs, and if consumers do not decrease consumption, not considered to be penalty. Another sub group of IBP are mandatory programs. I/C and CAP included in this sub group, if consumers, who

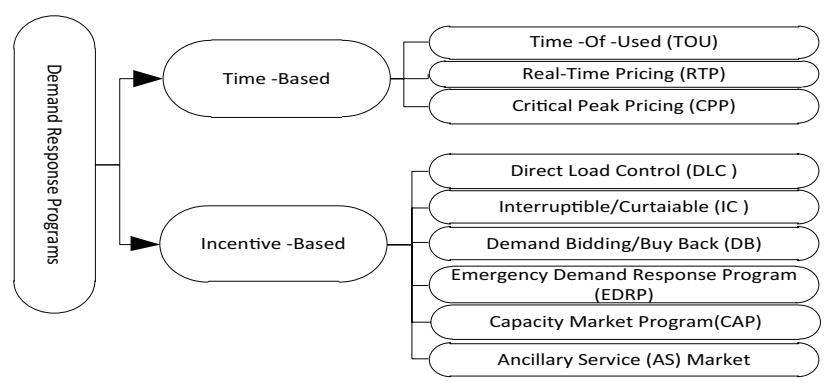

Figure 1. Demand response chart. 
have already participated in this program, fail to keep their demand response in the authorized level, are expected to penalize. In DB program large consumers arrange for load reductions offer at prices at which they are ready to be reduced, or to determine how much the load would be prepared to reduce at announced prices. In AS programs consumers can bid load reductions in operating reserves electricity market. In this paper, we have focused on DLC program.

\section{Mathematical Model}

\subsection{Demand's Price Elasticity and DLC Program}

Demand sensitivity concerning the price is defined as the elasticity [21]:

$$
e=\frac{\rho_{0}}{q_{0}} \bullet \frac{\partial q}{\partial \rho}
$$

where, (e) The elasticity of demand, $q$ energy demand $(M w h), \rho$ energy prices $(\$ / M w h), q_{0}$ initial demand, $\rho_{0}$ initial price. By definition, the elasticity of demand for the $i^{\text {th }}$ interval to interval $j$ is defined as:

$$
e(i, j)=\frac{\rho_{0}(j)}{q_{0}(i)} \bullet \frac{\partial q(i)}{\partial \rho(j)}
$$

It shows how consumer price changes in the $i^{\text {th }}$ interval due to change consumption in the interval $j$. In a period when price increases, Consumers tend to use energy is reduced or willing to transfer loads to another time interval if possible. Always, Cross-elasticity $(i \neq j)$ is positive, and own elasticity $(i=j)$ is negative. If price of electricity vary during different periods, the demand response can be one of the following:

Some consumption could be moved from the peak period to the off-peak or low periods (e.g. industrial loads). Such behaviour is named multi period sensitivity and it is evaluated by "cross-elasticity" which is positive. Several loads are not able to move from one period to another (e.g. lighting loads) and they could be only on or off. So, such loads have sensitivity just in a single period and it is called "self-elasticity", and it has a negative value [14].

DLC programs denote programs in which a utility or system operator remotely shuts down or local reliability contingencies in exchange for an incentive payment or cycles a customer's electrical equipment on short notice to address system or bill credit. In this paper we have used of the single period elastic load model. The load consumption considering DLC and value of incentive is given by the following equations [15]:

Suppose that:

$L(t)=$ Customer demand in $\mathrm{t}^{\text {th }}$ hour (MWh).

$L_{0}(t)=$ Initial Customer demand in $t^{\text {th }}$ hour (MWh).

$\rho(t)=$ Spot electricity price in $t^{\text {th }}$ hour (\$/MWh).

$\rho_{0}(t)=$ Initial Spot electricity price in $t^{\text {th }}$ hour $(\$ / M W h)$

$A(t)=$ Incentive in $t^{\text {th }}$ hour $(\$ / M W h)$.

$B(L(t))=$ Customer's income in $\mathrm{t}^{\text {th }}$ hour $(\$)$.

$\mathrm{e}=$ self-elasticity

And also suppose that the customer changes its demand from $L_{0}(t)$ (initial value) to $L(t)$, based on the value of price to initial price.

$$
\Delta \mathrm{L}(t)=\mathrm{L}(t)-\mathrm{L}_{0}(t)(\mathrm{Mwh})
$$

Therefore, the customer's benefit, $S(\$)$, for $t^{\text {th }}$ hour will be as follow:

$$
\mathrm{S}(\mathrm{L}(\mathrm{t}))=\mathrm{B}(\mathrm{L}(\mathrm{t}))-(\mathrm{L}(\mathrm{t}) \bullet \rho(\mathrm{t}))
$$
To maximize the customer's benefit, $\frac{\partial S}{\partial L(t)}$ should be
equal to zero:

$$
\begin{aligned}
& \frac{\partial S}{\partial L(t)}=\frac{\partial B(L(t))}{\partial L(t)}-\rho(t)=0 \\
& \frac{\partial B(L(t))}{\partial L(t)}=\rho(t)
\end{aligned}
$$

The most benefit-function used, is the quadratic benefit function:

$$
B(L(t))=B_{0}(t)+\rho_{0}(t)\left[L(t)-L_{0}(t)\right] \bullet\left\{1+\frac{L(t)-L_{0}(t)}{2 \bullet e(i, i) \bullet L_{0}(t)}\right\}
$$

Where:

$B_{0}(t)=$ Benefit when the demand is at nominal value $L_{0}(t)$

$\rho_{0}(t)=$ Nominal electricity price when the demand is nominal. Considering (6) and (7):

$$
\rho(t)=\rho_{0}(t) \bullet\left\{1+\frac{L(t)-L_{0}(t)}{e(i, i) \bullet L_{0}(t)}\right\}
$$


Therefore, customer's consumption considering time of used program will be as follow:

$$
L(t)=L_{0}(t) \bullet\left\{1+\frac{e(i, i) \bullet\left[\rho(t)-\rho_{0}(t)\right]}{\rho_{0}(t)}\right\}
$$

In the above equation, if $L(t)$ be equal to $L_{0}(t)$, the electricity price will not change and price elasticity will be equal to zero.

So, incentive prize, $\mathrm{P}(\$)$, due to running DLC will be as:

$$
P(\Delta L(t))=A(t) \bullet \Delta L(t)
$$

Therefore, the customer's benefit, $\mathrm{S}(\$)$, for $\mathrm{t}^{\text {th }}$ hour will be as follow:

$$
\mathrm{S}(\mathrm{L}(\mathrm{t}))=\mathrm{B}(\mathrm{L}(\mathrm{t}))-\mathrm{L}(\mathrm{t}) \bullet \rho(\mathrm{t})+\mathrm{P}(\Delta \mathrm{L}(\mathrm{t}))
$$
To maximize the customer's benefit, $\frac{\partial S}{\partial L(t)}$ should be
equal to zero:

$$
\begin{aligned}
& \frac{\partial S}{\partial L(t)}=\frac{\partial B(L(t))}{\partial L(t)}-\rho(t)+\frac{\partial P(\Delta L(t))}{\partial L(t)}=0 \\
& \frac{\partial B(L(t))}{\partial L(t)}=\rho(t)+A(t)
\end{aligned}
$$

Considering (7) and (13):

$$
\begin{aligned}
& \rho(t)+A(t)=\rho_{0}(t) \bullet\left\{1+\frac{L(t)-L_{0}(t)}{e(i, i) \bullet L_{0}(t)}\right\} \\
& \rho(t)-\rho_{0}(t)+A(t)=\rho_{0}(t) \bullet\left\{\frac{L(t)-L_{0}(t)}{e(i, i) \bullet L_{0}(t)}\right\}
\end{aligned}
$$

Therefore, customer's consumption considering DLC program will be as follow:

$$
L(t)=L_{0}(t) \bullet\left\{1+\frac{e(i, i) \bullet\left[\rho(t)-\rho_{0}(t)+A(t)\right]}{\rho_{0}(t)}\right\}
$$

\subsection{Wind Power Generation Output}

The power curve for sample wind turbine is illustrated in Figure 2, Wind speed $(v)$ lower than Cut-in wind speed $\left(v_{c}\right)$ and higher than Cut-out wind speed $\left(v_{c o}\right)$ produces zero power output, also the wind speed, which is between the rated speed $\left(v_{r}\right)$ and the cut-out speed $\left(v_{c o}\right)$ produces the rated power.

Then predicted wind power determined using the following power curve of a wind turbine $[22,23]$ :

$$
P(v)=\left\{\begin{array}{l}
P_{r} \bullet \frac{v^{2}-v_{c}^{2}}{v_{r}^{2}-v_{c}^{2}} \stackrel{\text { if }}{\longrightarrow} v_{c} \leq v \leq v_{r} \\
P_{r} \stackrel{\text { if }}{\longrightarrow} v_{r} \leq v \leq v_{c o} \\
0 \stackrel{\text { if }}{\longrightarrow} \text { otherwise }
\end{array}\right.
$$

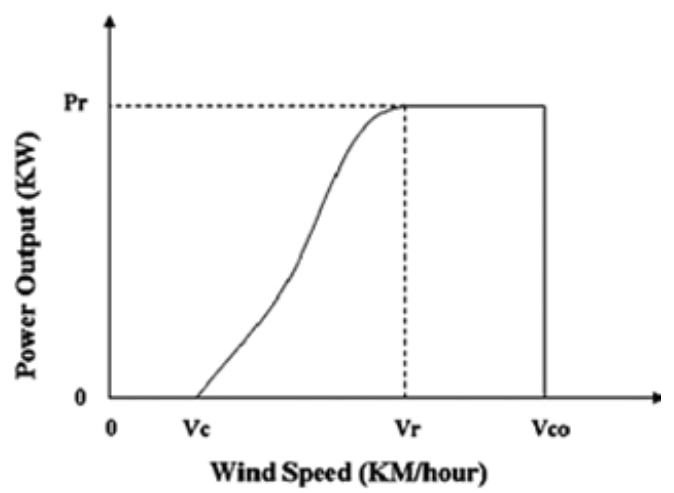

Figure 2. Wind turbine power curve.

where:

$\mathrm{P}(v)=$ Wind turbine power output in wind speed $v$.

$\mathrm{P}_{\mathrm{r}}=$ Wind turbine rated Power $(\mathrm{kw})$.

Hourly error is determined by comparing the real wind power with the predicted wind power. Distribution scenarios of probability of frequency of error occurrence are considered model wind power uncertainty.

\subsection{Virtual Power Plant Bidding Strategy in Day Ahead Power Market}

In Day Ahead (DA) energy markets both suppliers and consumers make hourly submissions to the market manager/operator. Through conjunction of the supply and demand functions/curves, the Market Clearing Price (MCP) is obtained for each hour. The imbalances can be compensated in a subsequent balancing market near the real-time operation. The settlement procedure includes paying the suppliers on the basis of their actual generations. The power imbalances caused by the suppliers are penalized [16]. The suggested objective function for CVPP offering model in day ahead power market is shown by the equation (18). The first part of this equation represents the amount of wind power generation revenue and penalty in power market. The revenue and cost of performance demand response program is represents by second and third part. The constraints of the wind power generation are shown in equations (19)-(24). The constraints of demand response program are defined as equations (25)-(26). In fact, this optimization problem seeks to maximize the expected profit of CVPP in day ahead electricity market based on the wind power and demand response scenarios and market situations. Owing to the stochastic nature of wind power, wind power prediction may have some errors. Since the WPP participates 
in the day ahead electricity market based on wind power predicted scenarios, it has to consider imbalance penalties in its optimization model.

$$
\begin{aligned}
& \operatorname{PROFIT}_{C V P P}=\sum_{t=1}^{n_{t}} \sum_{s=1}^{n_{s}} \lambda_{t}^{\text {energy }} \bullet P_{t}^{\text {Forecassed }}+\lambda_{t}^{\text {spot }} \bullet \pi_{t s}^{+} \bullet \Delta_{t s}^{+}-\lambda_{t}^{\text {spot }} \bullet \pi_{t s}^{-} \bullet \Delta_{t s}^{-} \\
& +\sum_{t=1}^{n_{t}} \sum_{s=1}^{n_{s}} \lambda_{t}^{\text {spot }} \bullet P_{t}^{D R}-\sum_{t=1}^{n_{t}} \sum_{s=1}^{n_{s}} A(t) \bullet P_{t}^{D R}
\end{aligned}
$$

where:

PROFIT $_{\text {CVPP }}$ : Total profit of CVPP(\$)

$\lambda_{t}^{\text {energy: }}$ Energy price(\$/Mwh); $\lambda_{t}^{\text {spot: }}$ Spot price $(\$ / M w h)$

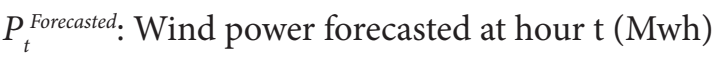

$\Delta_{t s}^{+}$Positive imbalance; $\Delta_{t s}^{-}$Negative imbalance

$\pi_{t s}$ : Scenario probability; $P_{t}^{D R}$ : Demand response power $(\mathrm{Mw}) ; t$ : time; $s$ : senario

St.

$$
\begin{aligned}
& 0 \leq P_{t s}^{w p p} \leq P_{t s}^{\text {Forecasted }} \\
& \Delta_{t s}=P_{t s}^{W P P}-P_{t s}^{\text {Forecasted }} \\
& \Delta_{t s}=\Delta_{t s}^{+}-\Delta_{t s}^{-} \\
& P_{t s}^{\text {Forecasted }} \leq \Delta_{t s}^{+} \leq P_{\max }^{W P P} \\
& P_{t s}^{W P P} \leq \Delta_{t s}^{-} \leq P_{t s}^{\text {Forecasted }} \\
& \text { Error }_{t}^{W} \bullet P_{t}^{\text {Forecasted }} \leq P_{t s}^{D R} \leq \alpha \bullet L_{t s}^{\text {Forecasted }} \\
& P_{t s}^{D R} \leq L_{t s}^{0}-L_{t s}^{0}\left[1+e \bullet\left[\frac{\lambda_{t}^{\text {energy }}-\lambda_{t, 0}^{\text {energy }}+A(t)}{\lambda_{t, 0}^{\text {energy }}}\right]\right] \\
& 0 \leq A(t) \leq \lambda_{t}^{\text {energy }}
\end{aligned}
$$

where:

$P_{t s}^{W P P}:$ Real wind power generation(Mwh)

Error ${ }_{t}^{w}$ : Error of wind power forecasted

$\alpha$ : Share of contributing load in DLC demand response program

\section{Case Study}

\subsection{Data}

In this section, the CVPP without DLC, with 5\% DLC and $10 \%$ DLC are simulated and investigated to show the economical and technical benefits of DLC programs. A 50MW wind farm, which consists of twenty $2.5 \mathrm{MW}$ commercial wind turbines and sample load curve are considered. The wind speed and power data considered using the Sotavento wind farm, in Spain [17]. The case studies are simulated for one sample day which is show in Figure 3. The energy price and spot price of the Spanish electricity market is used in this section, which can be found in [18] and shown in Figure 4. Wind power forecast error for day ahead in single wind farms based on historical error is defined as a distribution function and applied to the model. The imbalance prices are considered as deterministic given equal to spot price. The load curve [19] is shown in Figure 5. In this paper assumed imbalance is usually negative and self-elasticity equal to $(-0.2)$ [20]. The proposed optimization model is solved using NLP in GAMS software package.

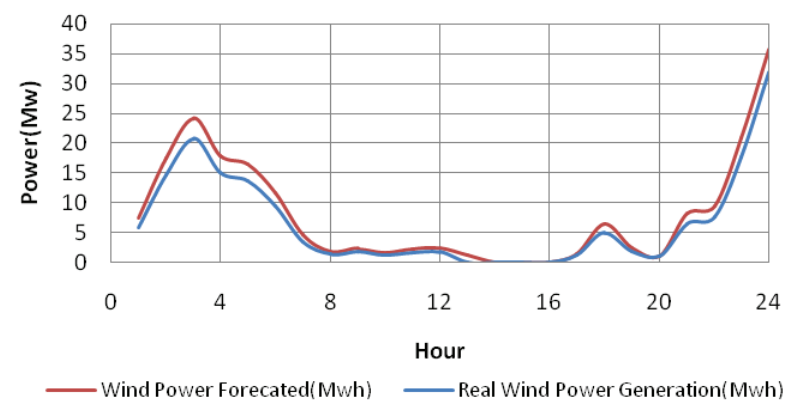

Figure 3. Wind power generation.

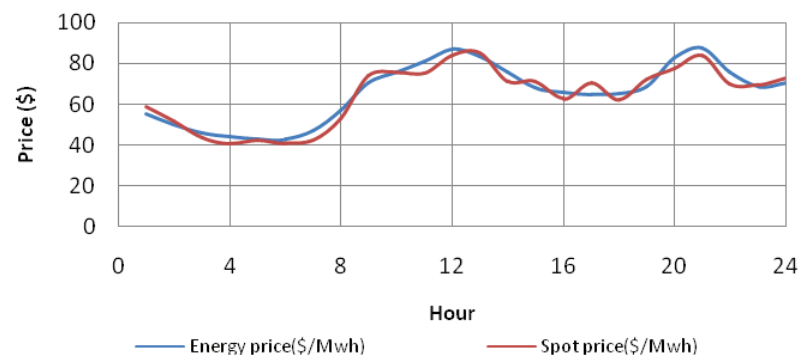

Figure 4. Energy and Spot prices.

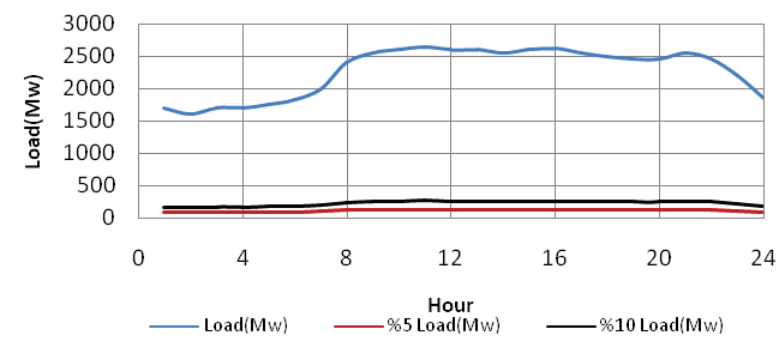

Figure 5. Load curve. 


\subsection{CVPP Operation Results}

In this section CVPP with three scenarios was investigated. Assumed load amount share of contributing load in DLC demand response was equal to $\alpha=0 \%, \alpha=5 \%$ and $\alpha=10 \%$ respectively. The profit maximization of the CVPP in electricity market was based on self-scheduling method. The profit of CVPP maximized by contributing to electricity market and pays penalty equal to spot price market for any imbalance, based on wind power forecast error. Expected profit objective function of CVPP was optimized by NLP in Gams software. The daily total expected profit and the optimum incentive payment for different $\alpha$ was obtained from this optimization. Comparison of the results was reported in Table 1. With reference to Table 1, it was observed that with increased contributing load share in DLC demand response program increased profit and decreased incentive payment, $\mathrm{A}(\mathrm{t})$. With reference to Figure 6 and Figure 7, it was observed that the forecasting error of WPP was compensated by DLC demand response program under this scenario.

\section{Conclusion}

This paper has focused on wind power generation integrated by demand response as a commercial virtual power plant, CVPP. Self-scheduling method has been used to derive maximum expected profit from the Energy Market. Expected profit objective function of CVPP operations has optimized by NLP in Gams software. The expected profit of CVPP with contributing load in DLC demand response program with $\alpha=0 \%, \alpha=5 \%$ and $\alpha=10 \%$ has

Table 1. CVPP Operation daily profit comparison

\begin{tabular}{lllr}
\hline Case & $\alpha=0 \%$ & $\alpha=5 \%$ & $\alpha=10 \%$ \\
\hline Profit $(\$)$ & 7723.30 & 9339 & 9600.50 \\
$\mathrm{~A}(\mathrm{t})$ & 0.00 & 536.73 & 275.22 \\
\hline
\end{tabular}

been studied. The expected profits for CVPP with $\alpha=0 \%$, $\alpha=5 \%$ and $\alpha=10 \%$ are $\$ 7723.30, \$ 9339$ and $\$ 9600.50$ respectively. The incentive payment, $\mathrm{A}(\mathrm{t})$ to contributing load for $\alpha=0 \%, \alpha=5 \%$ and $\alpha=10 \%$ are $\$ 0, \$ 536.73$ and $\$ 275.22$ respectively. It was found out that with increasing contributing load share in DLC demand response program increases profit and decreases incentive payment, $\mathrm{A}(\mathrm{t})$. Hence it is concluded that contributing load to DLC demand response programs yields better expected profit

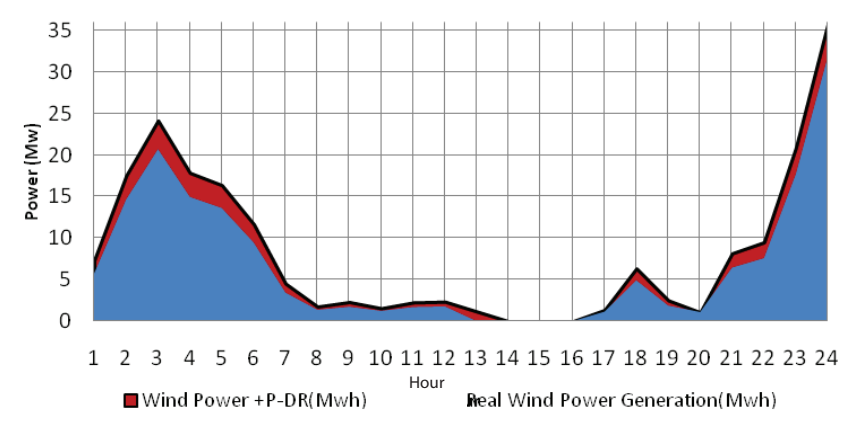

Figure 6. Compensate wind power error by P-DR.

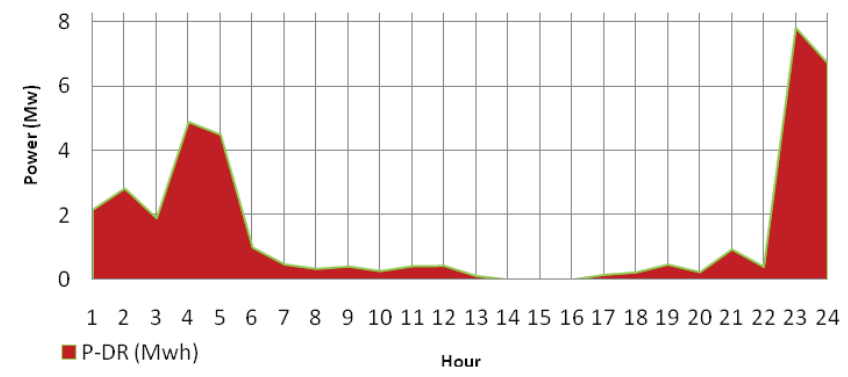

Figure 7. Contributing DLC demand response program.

for CVPP. It also compensates wind power forecasted error.

\section{References}

1. Alishahi E, Moghaddam M P et al. (2012). A system dynamics approach for investigating impacts of incentive mechanisms on wind power investment, Renewable Energy, vol 37(1), 310-317.

2. Moura P S, De Almeida A T et al. (2010). The role of demand-side management in the grid integration of wind power, Applied Energy, vol 87(8), 2581-2588.

3. Braun M (2009). Virtual power plants in real applications, Sixth Research Framework Programme of the European Union for the FENIX project (SES6-518272), Available from: http://www.iwes.fraunhofer.de

4. Corera J (2009). Flexible electricity networks to integrate the expected energy evolution, FENIX project, Bilbao, Spain.

5. Pudjianto D, Ramsay C et al. (2007). Virtual power plant and system integration of distributed energy resources, Renewable Power Generation, IET, vol 1(1), 10-16.

6. Chambers A, Schnoor B et al. (2001). Distributed generation: a non-technical guide, PennWell Books, Oklahoma, USA, Chapter 1, 1-19.

7. IEA Demand Side Management Programme Report (2009). Integration of demand side management, distributed gen- 
eration, renewable energy sources and energy storages, Available from: http://www.ieadsm.org

8. ISO Technical Report (2009). Alternate Route: Electrifying the Transportation Sector, New York, USA.

9. Moghaddam M P, Baboli E T et al. (2010). Flexible load following the wind power generation, 2010 IEEE International Energy Conference and Exhibition, 802-807.

10. Usaola J, and Angarita J (2007). Bidding wind energy under uncertainty, International Conference on Clean Electrical Power, ICCEP'07, IEEE, 754-759.

11. Ackermann T. (2005). Wind power in power systems, John Wiley, Chichester, UK, vol 140, Chapter 4, 47-72.

12. Galloway S, Bell G et al. (2006). Managing the risk of trading wind energy in a competitive market, IEE ProceedingsGeneration, Transmission and Distribution, vol 153(1), 106-114.

13. Federal Energy Regulatory Commission (FERC) (2006). Assessment of demand response and advanced metering, Department of Energy, Washington, DC, USA, Available from: http://www.ferc.gov/legal/staff-reports/demand-response.pdf.

14. Kirschen D (2003). Demand-side view of electricity markets, IEEE Transactions on Power Systems, vol 18(2), $520-527$.

15. Aalami H A, Moghaddam M P et al. (2010). Modeling and prioritizing demand response programs in power markets, Electric Power Systems Research, vol 80(4), $426-435$.

16. Garcia-Gonzalez J, de la Muela R R et al. (2008). Stochastic joint optimization of wind generation and pumped-storage units in an electricity market, IEEE Transactions on Power Systems, vol 23(2), 460-468.

17. StoventoWindfarm (2013). Available from: http://www. sotaventogalicia.com

18. OMEL (2013). Market operator of the electricity market of Mainland Spain, Available from: http://www.omel.es

19. Aalami H, Yousefi G R et al. (2008). A MADM-based support system for DR programs, Universities Power Engineering Conference, $43^{\text {rd }}$ International Universities Power Engineering Conference, UPEC 2008, 1-7.

20. De Jonghe C, Hobbs B F et al. (2012). Optimal generation mix with short-term demand response and wind penetration, IEEE Transactions on Power Systems, vol 27(2), 830-839.

21. Kirschen D, Strbac G et al. (2004). Fundamentals of power system economics, John Wiley \& Sons, London, UK.

22. Stevens M J M, and Smulders P T (1979). The estimation of the parameters of the Weibull wind speed distribution for wind energy utilization purposes, Wind Engineering, vol 3(2), 132-145, Chapter 2, 16-17.

23. Pallabazzer R (2004). Previsional estimation of the energy output of windgenerators, Renewable Energy, vol29(3), 413420 . 